\title{
A PROSPECTIVE STUDY OF 30 CASES OF SURGICALLY MANAGED APPENDICULAR MASS
}

Halagana Nagaraj ${ }^{1}$, Ratikanta Narayana Raikar ${ }^{2}$, Rajalakshmi ${ }^{3}$, Arshiva Taj ${ }^{4}$, Asha M.N5 , Aneeta Mutgi ${ }^{6}$, Nikita V. Shivannagol7

\section{HOW TO CITE THIS ARTICLE:}

Halagana Nagaraj, Ratikanta Narayana Raikar, Rajalakshmi, Arshiva Taj, Asha M.N, Aneeta Mutgi, Nikita V. Shivannagol. "A Prospective study of 30 cases of Surgically Managed Appendicular Mass". Journal of Evolution of Medical and Dental Sciences 2014; Vol. 3, Issue 08, February 24; Page: 1837-1840

DOI: $10.14260 /$ jemds/2014/2066

ABSTRACT: BACKGROUND: A study of 30 surgically operated appendicular mass was conducted at SIMS and RC with respect to complication, hospital stay and recovery. METHOD: 30 patients were taken for case study who were surgically treated for appendicular mass soon after the diagnosis and assessed for recovery time, hospital stay and complications. CONCLUSION: Emergency appendicectomy to treat appendicular mass should be considered as an option as it decreases the hospital stay, avoids repeated exposure to risks involved in surgery as in interval appendicectomy and gives a better recovery as the foci of infection is removed.

KEYWORDS: appendicular mass, surgical intervention, fecal fistula.

INTRODUCTION: Appendicular mass is a commonest complication of acute appendicitis. It is an inflamed appendix with an adherent covering of omentum and small bowel. It presents with the history severe pain localized to right iliac fossa, vomiting and fever and clinically palpable mass develops in right iliac fossa in $48 \mathrm{hrs}$. The treatment of appendicular mass is controversial. It is changing from the traditional approach of initial conservative treatment followed by interval appendicectomy to immediate appendicectomy ${ }^{1,2}$.

In our institution we have observed after the study of 30 cases that with the advancement in all the fields in medicine that early surgical exploration of the appendicular mass can be done with satisfactory results and it considerably reduces the total hospital stay and obviates the need for a second admission. ${ }^{3}$ And non-operative management is not always successful. ${ }^{4-5}$ In addition, the patient may suffer a recurrence of appendicitis after being discharged from the hospital.6, 7

MATERIAL AND METHODS: 30 cases of appendicular mass were considered for the study from the year 2009 to 2012 .

Age group of these of patients was ranging from 17 to 48 yrs.; out of these cases 18 were male 12 were female.All the 30 cases presented with pain abdomen as their chief complaints. Out of the 30 patients 22 patients had associated history of vomiting and 12 with fever.

After thorough clinical and laboratory investigations and with USG confirmation of appendicular mass these cases were taken up for emergency appendicectomy. The average length of stay with conservative treatment varied from 10 to 18 days ${ }^{10}$ with a further eight days required for elective appendicectomy. Our patients had an average stay of six to 10 days except in one patient where post-operative stay extended upto 18 days. Follow up of these patients was done upto 3 months and found that follow up period was uneventful. 


\section{ORIGINAL ARTICLE}

\section{Complications following surgery:}

\begin{tabular}{|c|c|c|}
\hline SYMPTOM & NUMBER & PERCENTAGE \\
\hline Pain abdomen & 30 & $100 \%$ \\
\hline Vomiting & 22 & $73.34 \%$ \\
\hline Fever & 12 & $40 \%$ \\
\hline
\end{tabular}

\section{Fecal fistula seen in 1 in 30 cases}

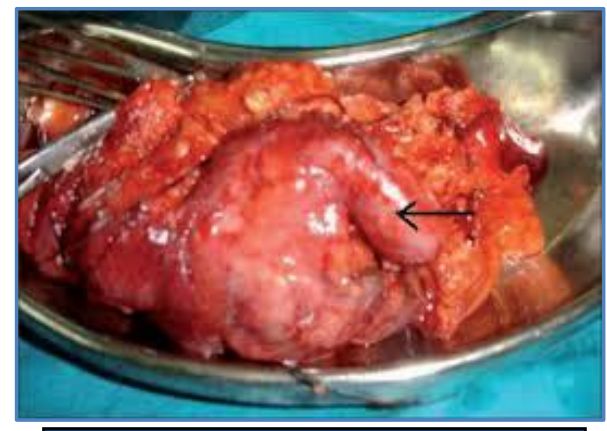

Fig. 1: Showing Appendix

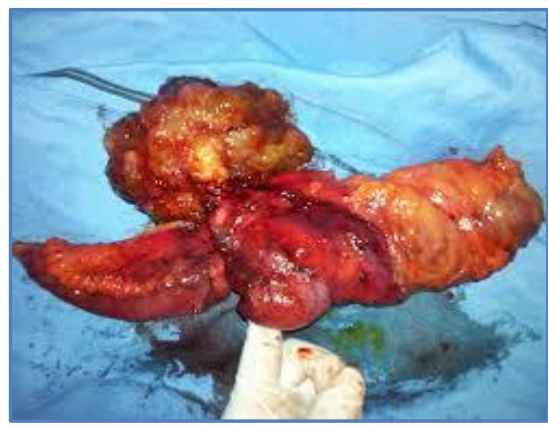

Fig. 2: Showing Appendicular mass

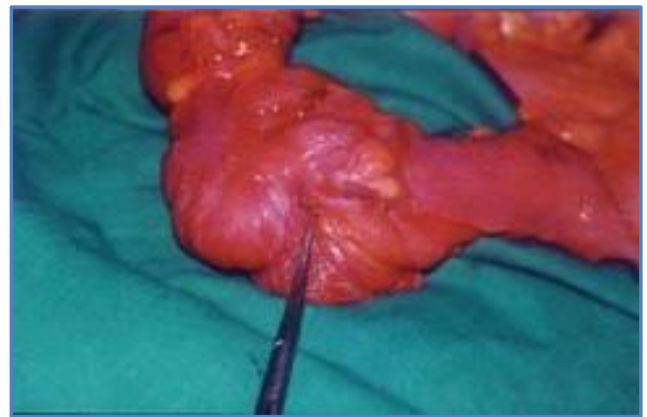

Fig. 3: Showing Appendicular

DISCUSSION: Reports on conservative vs. early operative treatment of appendicular mass and abscess are difficult to compare and, certainly, no single prospective and randomized trial has been carried out to clarify the possible superiority of any of these treatment plans. One main problem in comparing existing retrospective results is the lack of consistency in using the terms appendiceal mass and appendiceal abscess. As emphasized by McPherson and Kinmonth, ${ }^{11}$ the two terms are not synonymous, appendiceal mass thus signifying a palpable lump around an inflamed appendix that at operation might turn out to be either a phlegmon with adherent adjacent organs or a definite abscess. Studies of conservative management deal with both conditions, while most studies of early operation deal with the stage of abscess formation. Clinically it is not possible in most cases to distinguish with certainty between the two conditions, but in two recent reports about half of the patients presenting with a mass proved to have phlegmons at surgery3,11. In this way it becomes uncertain to what extent 
definite abscesses resolve spontaneously or need incision. It remains to -be shown if ultrasonography might clarify this point as proposed. ${ }^{3}$

Many controversies have been occurring lately regarding the line of management for appendicular mass. Which include conservative treatment with interval appendectomy to immediate appendicectomy. Conservative treatment could be considered as a good approach initially but the patient may suffer with recurrence. And conservative treatment with interval appendectomy increases the hospital stay and exposes the patients to risks involving surgery and anesthesia. In comparison to this immediate appendectomy can be considered as a safe procedure as it teats the cause by removing the focus of infection, reduces the hospital stay, $\mathrm{n}$ prevents from repeated surgical exposure.

\section{REFERENCES:}

1. Sanapathi PS, Bhattacharya D, Amori BJ. Early laparoscopic appendectomy for appendicular mass. Surg Endosc. 2002; 16:1783-5. [PubMed]

2. De U, Ghosh S. Acute appendicectomy for appendicular mass: A study of 87 patients. Ceylon Med J.2002; 47:117-8. [PubMed]

3. Jordan JS, Kovalcik PJ, Schwab CW. Appendicitis with a palpable mass. Ann Surg. 1981;193:227-9.[PMC free article] [PubMed]

4. Thomas DR. Conservative management of the appendix mass. Surgery. 1973; 73:67780. [PubMed]

5. Surana R, Puri P. Appendiceal mass in children. Pediatr Surg Int. 1995; 10:79-81.

6. Bagi P, Dueholm S. Nonoperative management of the ultrasonically evaluated appendiceal mass. Surgery. 1987; 101:602-5. [PubMed]

7. Oliak D, Yamini D, Udani VM, Lewis RJ, Vargas H, Arnell T. Nonoperative management of perforated appendicitis without periappendiceal mass. J Surg. 2000; 179:177-81. [PubMed].

8. Garg P, Dass BK, Bansal AR, Chitkara N. Comparative evaluation of conservative management versus early surgical intervention in appendicular mass: A clinical study. J Indian Med Assoc.1997; 95:179-80. [PubMed].

9. Puri P, Boyd E, Guiney EJ. Appendix mass in the very young child. J Pediatr Surg. 1981;16:557.[PubMed]

10. Vakilli C. Operative Treatment of Appendix Mass. Am J Surg. 1976; 131:312-4. [PubMed]

11. McPherson AG, Kinmonth JB. Acute appendicitis and the appendix mass. Br J Surg 1945; 32:365-370. 


\section{ORIGINAL ARTICLE}

\section{AUTHORS:}

1. Halagana Nagaraj

2. Ratikanta Narayana Raikar

3. Rajalakshmi,

4. Arshiva Taj

5. Asha M.N.

6. Aneeta Mutgi

7. Nikita V. Shivannagol

\section{PARTICULARS OF CONTRIBUTORS:}

1. Associate Professor, Department of General Surgery Shimogga Institute of Medical Sciences and Research Centre, Shivamogga, Karnataka, India.

2. Assistant Professor, Department of General Surgery Shimogga Institute of Medical Sciences and Research Centre, Shivamogga, Karnataka, India.

3. Assisant Professor, Department of General Surgery Shimogga Institute of Medical Sciences and Research Centre, Shivamogga, Karnataka, India.

4. House Surgeon, Department of General Surgery Shimogga Institute of Medical Sciences and Research Centre, Shivamogga, Karnataka, India.
5. House Surgeon, Department of General Surgery Shimogga Institute of Medical Sciences and Research Centre, Shivamogga, Karnataka, India.

6. House Surgeon, Department of General Surgery Shimogga Institute of Medical Sciences and Research Centre, Shivamogga, Karnataka, India.

7. House Surgeon, Department of General Surgery Shimogga Institute of Medical Sciences and Research Centre, Shivamogga, Karnataka, India.

\section{NAME ADDRESS EMAIL ID OF THE} CORRESPONDING AUTHOR:

Dr. Halagana Nagaraj,

"Shushrutha" House No. 126-b block, Gopala Road Extension, Shimogga.

E-mail: drhalaganagaraj55@gmailcom

Date of Submission: 23/01/2014. Date of Peer Review: 24/01/2014. Date of Acceptance: 10/02/2014. Date of Publishing: 18/02/2014. 